\title{
Enhancing adherence in trials promoting change in diet and physical activity in individuals with a diagnosis of colorectal adenoma; a systematic review of behavioural intervention approaches
}

\author{
Deborah McCahon ${ }^{1 *}$, Amanda J. Daley$^{1}$, Janet Jones ${ }^{1}$, Richard Haslop², Arjun Shajpal ${ }^{3}$, Aliki Taylor ${ }^{1}$, \\ Sue Wilson ${ }^{1}$ and George Dowswell
}

\begin{abstract}
Background: Little is known about colorectal adenoma patients' ability to adhere to behavioural interventions promoting a change in diet and physical activity. This review aimed to examine health behaviour intervention programmes promoting change in diet and/or physical activity in adenoma patients and characterise interventions to which this patient group are most likely to adhere.

Methods: Searches of eight databases were restricted to English language publications 2000-2014. Reference lists of relevant articles were also reviewed. All randomised controlled trials (RCTs) of diet and physical activity interventions in colorectal adenoma patients were included. Eligibility and quality were assessed and data were extracted by two reviewers. Data extraction comprised type, intensity, provider, mode and location of delivery of the intervention and data to enable calculation of four adherence outcomes. Data were subject to narrative analysis.

Results: Five RCTs with a total of 1932 participants met the inclusion criteria. Adherence to the goals of the intervention ranged from 18 to $86 \%$ for diet and 13 to $47 \%$ for physical activity. Diet interventions achieving $\geq 50 \%$ adherence to the goals of the intervention were clinic based, grounded in cognitive theory, delivered one to one and encouraged social support.

Conclusions: The findings of this review indicate that behavioural interventions can encourage colorectal adenoma patients to improve their diet. This review was not however able to clearly characterise effective interventions promoting increased physical activity in this patient group. Further research is required to establish effective interventions to promote adherence to physical activity in this population.
\end{abstract}

Keywords: Adenomatous polyps, Colorectal Neoplasms, Exercise, Diet, Intervention studies, Patient adherence, Patient compliance, Behaviour, Review

\section{Background}

Colorectal cancer is the third most common cancer in the UK, the second most common cause of cancer death and its incidence [1] is increasing. Most colorectal cancers arise from polyps or adenomas, and high-risk adenomas (HRA) are the most likely to become cancerous [2]. One of the aims of the National Health Service

\footnotetext{
* Correspondence: d.mccahon@bham.ac.uk

${ }^{1}$ Primary Care Clinical Sciences, School of Health and Population Sciences, University of Birmingham, Edgbaston, Birmingham B15 2TT, UK

Full list of author information is available at the end of the article
}

Bowel Cancer Screening Programme (NHSBCSP) is to detect and remove colorectal adenomas and thus improve survival [3]. Whilst adenoma removal reduces the risk of colorectal cancer, the underlying risk factors that influence recurrence of ademona remain and the recurrence rate for adenoma has been shown to be relatively high at around $40 \%$ after three years [4].

There is consistent evidence from observational studies that high ( $>500 \mathrm{~g}$ per week) dietary red and processed meat intake and low levels of physical activity cause colorectal cancer [5]. These risk factors are potentially 
modifiable and behavioural interventions which encourage change in diet and physical activity may reduce risk of recurrence of colorectal adenoma and development of colorectal cancer [6-9].

Through the introduction of the National Health Service Bowel Cancer Screening Programme the rates of detection of adenomas is likley to increase. As such identification of effective interventions to change behaviour associated with risk of colorectal adenoma in this patient group are becoming increasingly important.

Evidence suggests that interventions for populations at increased risk of disease are more likely to be successful than in healthy populations. Compared with the general population, patients with a previous diagnosis of colorectal adenoma are at increased risk of colorectal cancer. This patient population is different to the general population since they have received screening and surgical intervention to remove adenomatous polyps. As such, findings from trials of health behaviour interventions in the general population are unlikely to be generalisable to this patients group.

Previous systematic reviews of exercise and diet interventions for adults have focussed on different types of cancer, types of intervention and various outcomes [10-25]. Data derived from trials with cancer survivors may not however be applicable to this patient group either because colorectal adenomatous ploys are considered precursors to colorectal cancer.

Inadequate adherence in clinical trials contributes to significantly increased study costs, complicates statistical analysis and threatens study validity [26-28]. Clinical trials of behavioural interventions frequently suffer from low levels of adherence with estimates suggesting that between 25 and $50 \%$ of research participants are not adherent [26]. Broadly, adherence can be defined as the extent to which a trial participant acts in accordance with the instructions or recommendations of the research as specified in the study protocol.

The current literature review was undertaken to examine behavioural intervention programmes and determine adherence in RCTs promoting a reduction in consumption of red meat, elimination of processed meat and increased physical activity in individuals with a diagnosis of colorectal adenoma. The aim was to define diet and physical activity interventions to which colorectal adenoma patients are likely to adhere and to use these in the development of a large prospective RCT to assess whether the interventions are effective in changing health behaviour associated with risk of colorectal adenoma.

To achieve this aim it was necessary to i) identify RCTs of dietary and/or physical activity interventions promoting risk reduction in individuals with a diagnosis of colorectal adenoma, ii) summarise data related to protocol adherence and follow-up in these RCTs and iii) characterise the behavioural interventions or elements of these interventions which achieved and sustained maximum adherence.

\section{Review}

Search methods to identify relevant studies

An electronic search of eight databases (Pubmed, Cochrane, Medline, Embase, PsychINFO, HMIC, Cinahl and $\mathrm{BNI}$ ) was conducted to capture relevant publications (searches last conducted October 2012). Detailed search strategies were developed for each database (Table 1). Searches were limited to studies involving humans, in English language and published since 2000. Significant advancement in health behaviour research and technology has been made over recent years. This time frame was chosen to enable identification of trials of health behaviour interventions which are most applicable and relevant to a contemporary cohort of patients with colorectal adenoma. All retrieved articles were reviewed to identify additional, relevant RCTs. To ensure consistency in selection, the titles and abstracts of all papers retrieved via the searches were reviewed independently by two reviewers. Papers that did not fulfil the selection criteria were excluded. Full papers were obtained for the remaining studies and two reviewers read and independently applied the selection criteria. The two reviewers met to resolve any disagreement and reach consensus.

\section{Selection criteria Inclusion criteria}

(i) RCTs with a population of adults with a previous diagnosis of colorectal adenoma without a previous diagnosis of colorectal cancer.

(ii) RCTs which evaluated a behavioural intervention aiming to promote change in physical activity and/ or diet.

(iii) RCTs reporting data related to adherence as either a dichotomous or continuous variable.

Other outcomes of interest were retention, attrition and reasons for drop-out. RCTs were not excluded, however, if data related to these outcomes were not reported. Meta-analysis and systematic reviews were employed as sources of additional RCTs only.

\section{Exclusion criteria}

(i) RCTs in cancer patients or cancer survivors

(ii) RCTs of prevention in cancer patients

(iii)RCTs in which adherence data could not be extracted.

\section{Quality assessment}

The quality of each included RCT was assessed using the Critical Appraisal Skills Programme RCT checklist 
Table 1 Search terms

\begin{tabular}{|c|c|c|c|c|}
\hline Physical activity & Diet & Diet (Cont) & Compliance & Medical \\
\hline Exercis* & Diet $^{*}$ & Venison & Adherence & Cancer \\
\hline Exercise test & Diet restriction & Veal & Attitude to health & Adenoma* \\
\hline Exercise Tolerance & Diet, protein-restricted & Bacon & Behavio?r change & Colorect* \\
\hline Exercise therapy & Diet, fat-restricted & Sausages & Health behavio?r* & \\
\hline Physical endurance & Meat & Ham & Behavio?r modification & \\
\hline Physical exertion & Meat products & Hotdogs & Lifestyle changes & \\
\hline Physical fitness & Processed meat & Burgers & Patient* attitude & \\
\hline Physical activity & Red meat & Meatloaf & Patient* compliance & \\
\hline Physical training & Beef & Salami & Patient* reported outcomes & \\
\hline Motor activity & Lamb & Corned beef & Patient* participation & \\
\hline Movement & Pork & Tinned meat & Patient satisfaction & \\
\hline \multirow[t]{6}{*}{ Motion therapy } & Rabbit & & Readiness to change & \\
\hline & Venison & & Refusal to participate & \\
\hline & Veal & & & \\
\hline & Filters: & RCTs & & \\
\hline & & Humans & & \\
\hline & & English language & & \\
\hline
\end{tabular}

[29]. The quality of each included RCT was assessed by two of the reviewers ( $\mathrm{J}$ and $\mathrm{RH}$ ) with disagreements being resolved by discussion.

\section{Data extraction}

For each of the included RCTs, the paper was read in full by two reviewers (DM and AS). Data were extracted using a proforma specifically designed to record key information related to (i) study design (ii) population characteristics (iii) characteristics of the intervention including: type of intervention; mode, location and delivery of interventions; (iv) type of intervention provider (v) duration, intensity and frequency of the intervention. Data to enable calculation of adherence, frequency and methods of assessment of adherence and reasons for drop out were also extracted.

\section{Outcomes of interest of this review}

There were four main outcomes of interest of this review. Firstly, this review focused upon whether participants received/attended the intervention or its components, as described in the study protocol. Participants needed to have attended or engaged with each of the scheduled components of the intervention to be considered fully adherent in this outcome (intervention adherence). The second outcome of interest was the extent to which participants met the dietary and/or physical activity goals of the intervention. To be classified as adherent for this outcome, participants had to adhere to $\geq 50 \%$ of the diet and/or physical activity goals of the intervention. In health behaviour, it is difficult to give a precise definition or cut-off for when behaviour is deemed acceptable or not and this may vary from one context or population to another. A judgment on what such a cut-off might be was therefore required. Following much discussion and consideration, a minimum threshold of $50 \%$ was selected because this meant at least half of the sample had achieved at least half of the intervention. This was considered in light of the fact most people in the modern Western world are sedentary and do very little physical activity-so a shift in physical activity from very little to a minimum adherence of $50 \%$ of a physical activity intervention is not insignificant and even small changes in behaviour can be clinically worthwhile [30]. Given that participants who do well in the intervention are more likely to agree to follow-up, the third outcome was the follow up rate in the intervention group to enable comment upon the burden and acceptability of the intervention. A fourth and final outcome of interest was reported reasons for drop out.

\section{Methods of synthesis}

Since the focus of this review was identification and characterisation of behavioural interventions that maximise adherence in RCTs promoting behavioural change in adenoma patients, it was not appropriate to conduct a statistical analysis. Data were therefore subject to a narrative synthesis.

\section{Results of the search}

Figure 1 shows the outcome of the search process and application of the selection criteria. The electronic searches identified 2221 potentially relevant articles. Following removal of 805 duplicates, 1416 papers remained. A 


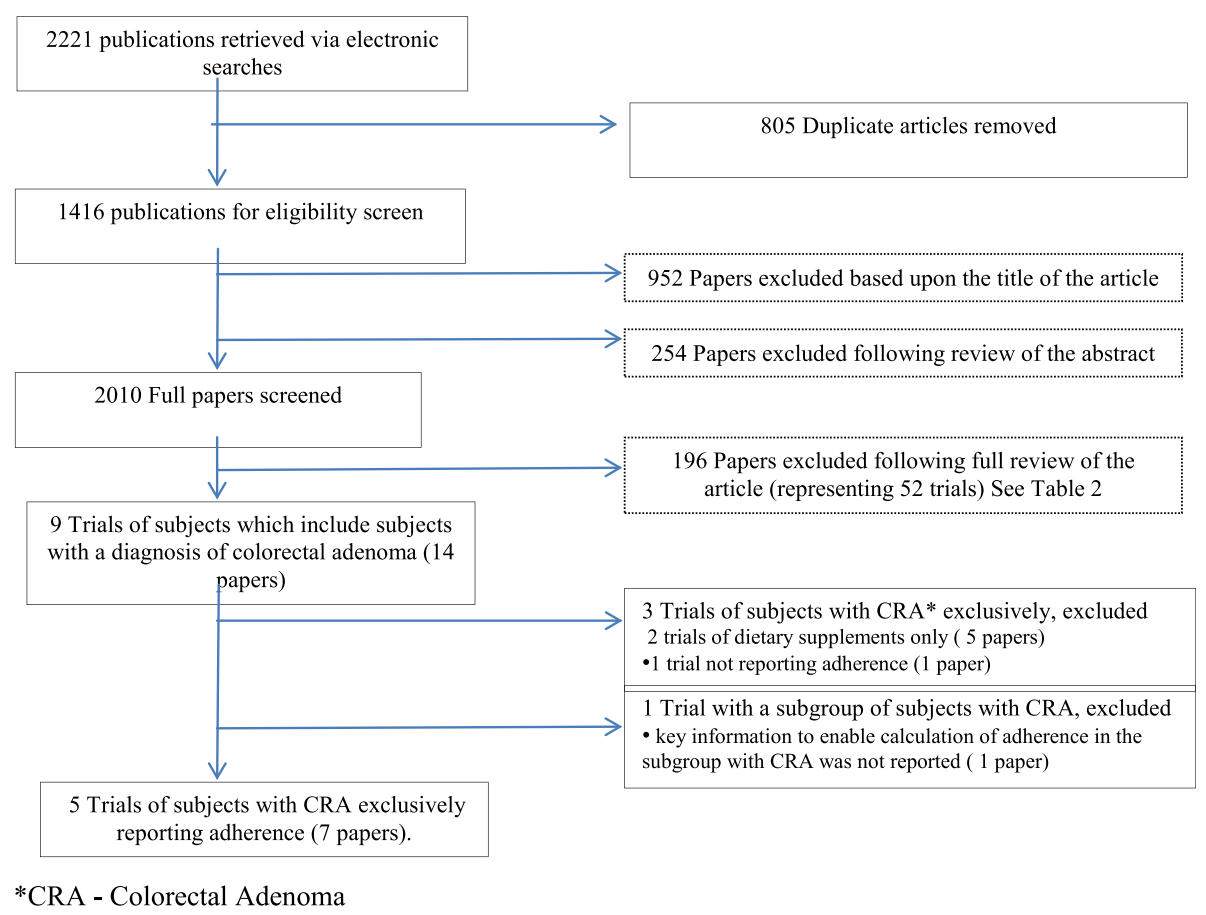

Fig. 1 Results of the search strategy

further 1206 of these articles were excluded following review of the title or abstract and 196 articles were excluded after a full review of the article. The reasons for exclusion are provided in Table 2 . The 14 remaining articles reported on nine RCTs which included individuals with a diagnosis of colorectal adenoma. Two of these RCTs were excluded from further review because they reported on RCTs of a dietary supplement and two RCTs were excluded because calculation of adherence was not possible. Five RCTs of a diet and/or physical activity intervention in colorectal adenoma patients were included in the current review [31-35].

\section{Description of included trials}

The characteristics of the five RCTs included are summarised in Tables 3, 4 and 5. The Minnesota Cancer

Table 2 Reason for exclusion of papers

\begin{tabular}{ll}
\hline Reason for exclusion & $\mathrm{n}(\%)$ \\
\hline Trials in breast cancer patients or survivors & $66(34)$ \\
Non RCT (includes systematic reviews) & $53(27)$ \\
Prevention trials/ trials in healthy subjects & $34(17)$ \\
Trials in prostate cancer patients or survivors & $11(6)$ \\
Trials in subjects with breast or prostate cancer & $6(3)$ \\
Trials in subjects with colorectal cancer & $6(3)$ \\
Trials in other cancer patients or survivors & $20(10)$ \\
Total & 196 \\
\hline
\end{tabular}

Prevention Research Unit (Minnesota CPRU) [31] trial and the Polyp Prevention Trial (PP trial) $[32,36]$ evaluated the impact of a behavioural intervention upon diet alone and the Bowel Health for Better Health (BHBH) [34], PREVENT [33] and the BeWEL [35] trials examined the impact of a behavioural intervention upon diet and physical activity (Tables 3, 4 and 5). In total, 1932 adenoma patients were randomised to receive these behavioural interventions. The majority of trial participants were aged 40 years or more, Caucasian and had received at least 15 years of education. All five publications reported that the behavioural interventions were successful in achieving change in diet and/or physical activity in adenoma patients (Table 3).

\section{Characteristic of the behavioural intervention}

In all five RCTs, participants were asked to meet or exceed current diet and/or physical activity recommendations for risk reduction at the general population level (Table 4).

The intervention in each of the five RCTs comprised a combination of behavioural, educational and affective approaches to promote behavioural change. Behavioural components of the intervention were based upon cognitive behavioural psychology and employed techniques such as negotiation and goal setting and encouraged planning, self monitoring and skill building. In addition, the Minnesota CPRU, PREVENT and BeWEL trials provided positive reinforcement and feedback. The Minnesota CPRU trial also used fridge magnets and birthday cards as 
Table 3 Characteristics of included trials

\begin{tabular}{|c|c|c|c|c|c|c|c|}
\hline $\begin{array}{l}\text { Author, pub date } \\
\text { and location }\end{array}$ & $\begin{array}{l}\text { Trial name and acronymEligibility } \\
\text { criteria }\end{array}$ & $\begin{array}{l}\text { Type of } \\
\text { intervention }\end{array}$ & $\begin{array}{l}\text { Trial duration and } \\
\text { number of } \\
\text { participants } \\
\text { recruited }\end{array}$ & Run in phase & $\begin{array}{l}\text { ITT } \\
\text { analysis }\end{array}$ & Characteristics of participants & $\begin{array}{l}\text { Summary of trial findings as reported in } \\
\text { publication }\end{array}$ \\
\hline Smith Warner $2000^{31}$ & $\begin{array}{l}\text { Minnesota cancer prevention } \\
\text { research unit diet intervention } \\
\text { trial-Minnesota CPRU }\end{array}$ & Diet & 12 months $n=100$ & No & Yes & Mean age 59 years & \multirow{2}{*}{$\begin{array}{l}\text { Individuals at high risk for development of } \\
\text { colorectal cancer can successfully increase } \\
F \& V \text { intake and maintain that increase over a } \\
\text { year period. }\end{array}$} \\
\hline USA & $\begin{array}{l}30-74 \text { years with a diagnosis of } \\
\text { colorectal polyps in preceding } \\
5 \text { years, no medical conditions or } \\
\text { chronic disease. }\end{array}$ & & & & & $\begin{array}{l}71 \% \text { male, } 99 \% \text { Caucasian, } \\
\text { mean number of years in } \\
\text { education was } 15\end{array}$ & \\
\hline Lanza $2001^{32}$ & Polyp Prevention Trial-PP trial & Diet & 4 years $n=1037$ & $\begin{array}{l}\text { Yes, } 4 \text { day } \\
\text { food record } \\
\text { and } \\
\text { frequency } \\
\text { survey }\end{array}$ & Yes & Mean age 61 years & \multirow[t]{2}{*}{$\begin{array}{l}\text { Free-living individuals can alter their eating } \\
\text { patterns in a significant way given } \\
\text { appropriate support }\end{array}$} \\
\hline USA & $\begin{array}{l}\geq 35 \text { years having removal of } \geq 1 \\
\text { colorectal adenomas removed } \\
\text { within past } 6 \text { months, no history of } \\
\text { colorectal cancer }\end{array}$ & & & & & $\begin{array}{l}66 \% \text { male, } 12 \% \text { minority } \\
\text { race, } 65 \% \text { higher than high } \\
\text { school education }\end{array}$ & \\
\hline Emmons $2005^{33}$ & Project PREVENT & $\begin{array}{l}\text { Diet and } \\
\text { physical } \\
\text { activity }\end{array}$ & 8 months $n=591$ & No & Yes & $\begin{array}{l}46 \% \text { aged } 40-59 \text { years and } \\
54 \% \text { aged over } 60 \text { years }\end{array}$ & \multirow{2}{*}{$\begin{array}{l}\text { PREVENT was effective in helping adenoma } \\
\text { patients to change and reduce behavioral } \\
\text { risk factors and behavioral change is possible } \\
\text { in this population }\end{array}$} \\
\hline USA & $\begin{array}{l}40-65 \text { years with a adenomatous } \\
\text { colon polyp removed within } \\
4 \text { weeks of recruitment, no history } \\
\text { of colorectal cancer }\end{array}$ & & & & & $\begin{array}{l}56 \% \text { male, } 83 \% \text { white, non } \\
\text { Hispanic, } 74 \% \text { higher than } \\
\text { high school education }\end{array}$ & \\
\hline Caswell $2009^{34}$ & $\begin{array}{l}\text { Bowel Health to Better Health- } \\
\text { BHBH }\end{array}$ & $\begin{array}{l}\text { Diet and } \\
\text { physical } \\
\text { activity }\end{array}$ & 12 weeks $n=41$ & No & $\begin{array}{l}\text { Not } \\
\text { explicit }\end{array}$ & Mean age 62 years & $\begin{array}{l}\text { Population is responsive to minimal contact } \\
\text { intervention to promote positive change in } \\
\text { diet }\end{array}$ \\
\hline \multirow[t]{2}{*}{ UK } & $50-74$ years & & & & & $71 \%$ male, $100 \%$ Caucasian & \\
\hline & $\begin{array}{l}\geq 1 \text { colorectal adenoma, no } \\
\text { evidence of colorectal carcinoma } \\
\text { or metaplastic or hyperplastic non- } \\
\text { adenomatous polyps }\end{array}$ & & & & & $\begin{array}{l}\text { Index of multiple deprivation } \\
\text { low } 20 \% \text {, medium } 40 \% \text {, high } \\
40 \%\end{array}$ & \\
\hline Anderson 2014UK ${ }^{35}$ & $\begin{array}{l}\text { BeWEL, 50-74 years, undergone } \\
\text { polypectomy for adenoma, able to } \\
\text { undertake physical activity }\end{array}$ & $\begin{array}{l}\text { Diet and } \\
\text { physical } \\
\text { activity }\end{array}$ & 12 months $n=163$ & No & Yes & $\begin{array}{l}\text { Mean age } 63.5 \text { years, } 74 \% \\
\text { male, } 100 \% \text { white, } 86 \% \text { equal } \\
\text { to higher than secondary } \\
\text { school education }\end{array}$ & $\begin{array}{l}\text { Significant weight loss can be achieved by a } \\
\text { diet and physical activity intervention } \\
\text { initiated within a national colorectal cancer } \\
\text { screening programme }\end{array}$ \\
\hline
\end{tabular}


Table 4 Characteristics of the intervention

Frequency, duration and Behavioural components of the Educational complements Affective components of the Mode and intensity of delivery of the

of the intervention

intervention

intervention (including

Smith Warner $2000^{31}{ }^{a}$ Increase fruit and vegetable intake to at least 5-8 servings per

\section{Nutrition counselling; goal setting, \\ verbal commitments to behavioura}

Written educational

materials; tip sheets,

intentions, skill development, planning cookbook and quarterly

and self monitoring. Memory aids;

newsletters

Frequent intervention visits with

nutritionist. Spousal support

encouraged.

Clinic based, individual sessions

provided by nutritionist at baseline,

month 1, 4, 7 and 10 .

and birthday cards.

Positive reinforcement and feedback

Lanza $2001^{32}$

Increase; daily fruit and vegetable consumption to 5-8 servings per day

daily fibre to $4.30 \mathrm{~g}$ fibre/mJ per day and consume $20 \%$ less energy from fat

Emmons $2005^{33} \quad 150$ min per week moderate intensity physical activity

ncrease daily fruit and vegetables to $\geq 5$ servings and weekly re meat to $\leq 3$ servings, increase vitamin and reduce alcohol intake and stop smoking

Caswell $2009^{34}$ 30 min physical activity per day, moderate

Consume $\geq 5$ serving of fruit and vegetable per day and increased daily fibre intake

Anderson $2014{ }^{35} \quad$ Target goal was $7 \%$ reduction in body weight
Individual counselling sessions to set personal goals, promote behaviour modification, motivate, skill building, and self monitoring

Motivational and goal setting initial counselling telephone call.

Skill building; planning and self monitoring

Printed progress reports with positive reinforcement and feedback

Tailored self help materials

Individual counselling assessment and goal setting session, personalised programme explained,

encouraged

Individual counseling with

motivational interviewing, goal setting positive reinforcement and feedback, self monitoring. Personalised energy prescription and tool kits provided
Provision of standardised education materials on nutrition and behavioura modification

\section{Annual education}

campaigns ( 1 for each diet goals)

cancer prevention literature, physical activity literature and fruit and

vegetable literature

Provision of a personal profile detailing risk status and highlighting the

importance of risk factor

reduction. Written materials;

sheet, guide book,

sheet

Help to develop coping skills, confidence and self efficacy.

Frequent group counselling sessions and telephone contact 6 monthly to resolve difficulties and discuss

progress

Motivational letters with specific tailored guidance based upon self efficacy and ability. Social support identified

Provision of the British Support from spouse/ friend encouraged. Motivational interviews so you want to lose weight exploring self assessed confidence for good
Insufficient data provided to enable calculation of the total number of hours counselling provided as part of the intervention

Clinic based individual and group sessions, weekly counselling for 6 weeks, biweekly for 6 weeks, monthly sessions thereafter. Year 2 . $3 \& 4$ monthly group sessions provided by a dietician.

$50 \mathrm{~h}$ of counselling in tota

Home based individual initial counselling telephone call followed by four calls at monthly intervals and four mail shots provided by a health educator.

$6.5 \mathrm{~h}$ of counselling in tota

Clinic based, individual $2 \mathrm{~h}$ session followed by 3 personalised mail shots, ad hoc telephone support provided by researchers. $2 \mathrm{~h}$ counselling in total

During the first 3 months trained lifestyle counsellors provided $3 \times 1 \mathrm{~h}$ individual face to face sessions. Sessions where home and/or clinic based. Followed by 9 monthly 15 min

by 9 monthly 15 min 
Table 4 Characteristics of the intervention (Continued)

150 min per week, $\quad$ (shopping bag, water bottles with

study logo, body weight sca

study logo, body

weight. Telephone contact offered to telephone calls. Total number of hours

moderate intensity

physical activity equipment (hand

discuss and overcome relapse

contact 5.25 h over 12 months

ncrease daily fruit and weights, DVDs)

to 5 portio

${ }^{a}$ Intervention is effective for promoting behavioural change in adenoma patients based upon $\leq 50$ adherence to the behavioural goals of the intervention 
Table 5 Adherence outcomes

\begin{tabular}{|c|c|c|c|c|c|}
\hline Author name and pub date & Intervention adherence & $\begin{array}{l}\text { Adherence to the behavioural } \\
\text { goals of the intervention }\end{array}$ & $\begin{array}{l}\text { Follow- } \\
\text { up rate }\end{array}$ & $\begin{array}{l}\text { Reasons for withdraw } \\
\text { from the intervention }\end{array}$ & $\begin{array}{l}\text { Method and frequency of assessment of } \\
\text { adherence }\end{array}$ \\
\hline \multirow[t]{3}{*}{ Smith Warner $2000^{31}$} & \multirow{3}{*}{$\begin{array}{l}\text { Based upon clinic attendance, } \\
\text { Attendance averaged } 93 \% \text { of } \\
\text { all clinic visits }\end{array}$} & \multirow{3}{*}{$\begin{array}{l}\text { a } 86 \% \text { met or exceeded the fruit } \\
\text { and vegetables goals of the } \\
\text { intervention }\end{array}$} & \multirow[t]{3}{*}{$88 \%$} & \multirow{3}{*}{$\begin{array}{l}2 \%(2 / 100) \\
\text { inappropriately } \\
\text { randomised, } 10 \%(10 / \\
100) \text { reason not reported }\end{array}$} & Baseline and at 3, 6, 9 and 12 months. \\
\hline & & & & & $\begin{array}{l}\text { Objective and subjective; diet records and } \\
\text { measurement of biological markers } \\
\text { (concentrations of carotenoids, lipids, sodium and } \\
\text { potassium). }\end{array}$ \\
\hline & & & & & Attendance monitored by intervention provider \\
\hline Lanza $2001^{32}$ & $\begin{array}{l}\text { Not specified and inadequate } \\
\text { data reported }\end{array}$ & Dietary goals met; & $89 \%$ & $4 \%(43 / 1037)$ died, & $\begin{array}{l}\text { Baseline and end of each year plus unannounced } \\
24 \mathrm{~h} \text { dietary recall in } 10 \% \text { of participants each } \\
\text { year. }\end{array}$ \\
\hline \multirow[t]{4}{*}{$\begin{array}{l}\text { Supplementary adherence data was } \\
\text { extracted from Sansbury } 2009^{36}\end{array}$} & & $\begin{array}{l}25.6 \%(210 / 821) \text { met } 9-12 \\
\text { goals }\end{array}$ & & \multirow{4}{*}{$\begin{array}{l}7 \%(71 / 1037) \text { withdrew } \\
\text { due to illness, moved } \\
\text { clinical centre, did not } \\
\text { wish to continue }\end{array}$} & \multirow{4}{*}{$\begin{array}{l}\text { Subjective and objective, food frequency } \\
\text { questionnaire, } 4 \text { day food records and } 24 \mathrm{~h} \\
\text { dietary recalls and measurement of biological } \\
\text { markers (concentrations of carotenoids and } \\
\text { lipids) }\end{array}$} \\
\hline & & $45 \%(366 / 821)$ met $4-8$ goals & & & \\
\hline & & $29.8 \%(245 / 821)$ met $0-3$ goals. & & & \\
\hline & & $\begin{array}{l}\text { Data reported did not allow } \\
\text { distinction between the } 3 \text { dietary } \\
\text { goals being evaluated }\end{array}$ & & & \\
\hline \multirow[t]{4}{*}{ Emmons $2005^{33}$} & \multirow{4}{*}{$\begin{array}{l}60 \% \text { received } 4 \text { to } 5 \\
\text { intervention telephone calls } \\
\text { conducted by health } \\
\text { educators }\end{array}$} & $\begin{array}{l}\text { Physical activity goals met by } \\
13 \%(76 / 591)\end{array}$ & $83 \%$ & \multirow[t]{4}{*}{ No dropout reported } & $\begin{array}{l}\text { Baseline and end of } 8 \text { month study period. } \\
\text { Subjective only- } 22 \text { item food frequency and } 24 \\
\text { item (CHAMPS) activity questionnaire. }\end{array}$ \\
\hline & & Dietary targets met; & & & \multirow{3}{*}{$\begin{array}{l}\text { Receipt of telephone calls monitored by } \\
\text { intervention provider }\end{array}$} \\
\hline & & $\begin{array}{l}20 \%(118 / 591) \text { met fruit and } \\
\text { vegetable goals }\end{array}$ & & & \\
\hline & & $\begin{array}{l}18 \%(104 / 591) \text { met red meat } \\
\text { goals }\end{array}$ & & & \\
\hline \multirow[t]{4}{*}{ Caswell $2009^{34}$} & \multirow[t]{4}{*}{$\begin{array}{l}\text { Insufficient data reported to } \\
\text { enable calculation }\end{array}$} & $\begin{array}{l}\text { Physical activity goals met by } \\
47 \%(15 / 32)\end{array}$ & \multirow[t]{4}{*}{$78 \%$} & \multirow[t]{4}{*}{$\begin{array}{l}\text { Dropout calculated as } \\
22 \%(9 / 41)\end{array}$} & \multirow{4}{*}{$\begin{array}{l}\text { Baseline and end of } 12 \text { week study period. } \\
\text { Subjective only-24 } \mathrm{h} \text { recall of fruit and } \\
\text { vegetables and food frequency questionnaire to } \\
\text { provide fibre consumption score (recorded mid } \\
\text { week) and } 7 \text { day physical activity recall } \\
\text { questionnaire. }\end{array}$} \\
\hline & & Dietary targets; & & & \\
\hline & & $\begin{array}{l}\text { a Fruit and vegetable goals met } \\
\text { by } 84 \%(27 / 32)\end{array}$ & & & \\
\hline & & a Fibre goals met by $53 \%(17 / 32)$ & & & \\
\hline \multirow[t]{2}{*}{ Anderson $20144^{35}$} & $\begin{array}{l}97 \% \text { attended all face to face } \\
\text { sessions ( } 3 \text { sessions) }\end{array}$ & $\begin{array}{l}\text { Data reported do not allow } \\
\text { calculation of the \% achieving } \\
150 \text { min per week, moderate } \\
\text { intensity physical activity }\end{array}$ & \multirow[t]{2}{*}{$91 \%$} & $\begin{array}{l}15 \text { participants withdrew, } \\
7 \text { gave no reason, }\end{array}$ & Baseline, 3 and 12 months. \\
\hline & $\begin{array}{l}59 \% \text { completed all of the } 9 \\
\text { planned telephone calls }\end{array}$ & Dietary targets; & & $\begin{array}{l}3 \text { withdrew due to health } \\
\text { concerns, } 1 \text { moved, } 2 \\
\text { reported personal reasons } \\
\text { and } 2 \text { were unable to } \\
\text { commit. }\end{array}$ & $\begin{array}{l}\text { Subjective and objective, self reported daily } \\
\text { diary and food frequency questionnaire } \\
\text { measurement body weight, waist } \\
\text { circumference, blood pressure, and of biological } \\
\text { markers (e.g., total, low and high density }\end{array}$ \\
\hline
\end{tabular}

Supplementary adherence data was extracted from Sansbury 2009 conducted by health

Insufficient data reported to 
Table 5 Adherence outcomes (Continued)

\section{$95 \%$ completed 5 of 9 \\ ${ }^{a}$ Fruit and vegetable goals met}

telephone calls

by $73 \%$ met.

a Intervention is effective for promoting behavioural change in adenoma patients based upon $\leq 50$ adherence to the behavioural goals of the intervention
SenseWear armband worn for 7 days to measure

daily expenditure and minutes of moderate

intensity exercise.

Trained lifestyle counsellor recorded attendance 
memory aids to maintain motivation and adherence. Tool kits of items such as pedometers and shopping bags and water bottles with trial logos were provided to participants of the BeWEL trial. Other equipment such as weighing scale, kitchen gadgets, physical activity equipment (e.g., exercise DVDs, hand weights and hoola hoops) were available, on loan also.

The educational materials delivered as part of the diet intervention generally provided information on nutrition and advice on ways to modify lifestyle to concur with target recommendations of the intervention. To highlight the importance of risk factor reduction, the PREVENT intervention provided information on personalised risk profiles in addition to distribution of general literature related to cancer prevention. Affective components of the intervention focused upon development of coping skills, confidence and self efficacy and provision of emotional support. In the Minnesota CPRU, BHBH and BeWEL trials support from a friend or partner was encouraged. Diet interventions were delivered by dedicated dieticians and/ or nutritionists. Trained lifestyle counsellors delivered the diet and physical activity intervention in the BeWEL trial. No exercise experts were involved with development and/ or delivery of the physical activity interventions. The interventions were delivered at individual counselling session in the Minnesota CPRU, PP, BHBH and BeWEL trials. The PREVENT trial employed a combination of individual and group sessions.

\section{Intervention adherence}

Intervention adherence was reported in the Minnesota CPRU, PREVENT and BeWEL trials only. Full intervention adherence was not, however, achieved in either of these trials. In the Minnesota CPRU trial, 93 \% intervention adherence was reported based upon attendance at all four intervention visits. The PREVENT trial reported that $60 \%$ of participants received four of the five counselling telephone calls. The BeWEL trial reported that $97 \%$ attended all the face to face sessions (3 sessions) and $59 \%$ completed all of the 9 planned telephone calls (Table 5).

\section{Adherence to the behavioural goals of the intervention}

Across the five RCTs, adherence to the dietary goals of the intervention ranged from 18 to $86 \%$ and adherence to the physical activity goals of the intervention ranged from 13 to $47 \%$ in the RCTs encouraging increased physical activity (Table 5).

In terms of effectiveness, the Minnesota CPRU, BHBH and BeWEL interventions were successful in achieving $\geq$ $50 \%$ adherence to the behavioural goals of the intervention. In the Minnesota CPRU, diet only interventions achieved $86 \%$ adherence to the fruit and vegetable goals of the intervention. The $\mathrm{BHBH}$ intervention, which promoted change in both diet and physical activity, was more effective with respect to diet, achieving $84 \%$ adherence to the fruit and vegetable goals, $53 \%$ adherence to the fibre goals and only $47 \%$ adherence to the physical activity goals of the intervention. The BeWEL diet intervention achieved $73 \%$ adherence to the fruit and vegetable goals. The PREVENT intervention, which promoted change in both diet and physical activity, was ineffective and failed to achieve adherence of $\geq 50 \%$ with respect to any of the behavioural goals of the intervention. The effectiveness of the PP intervention could not be defined because adherence was assessed at multiple points and divided into three subgroups based upon total number of goals met during the trial period (Table 5).

\section{Follow-up rate}

Follow-up rate was generally high, ranging from 78 to $89 \%$ in the RCTs of promoting change in diet and $78 \%$ $91 \%$ in RCTs encouraging change in both diet and physical activity. The reasons for withdraw or loss to follow-up were reported in the Minnesota CPRU, BeWEL and PP trials only. The Minnesota trial reported that $2 \%$ of participants were inappropriately randomized and a further $10 \%$ withdrew or were lost to follow-up. In the PP trial, $4 \%$ were lost to follow-up. In the BeWEL trial, $9 \%$ withdrew (Table 5).

\section{Reasons for drop out}

Only the BeWEL and PP trials reported reasons for drop out. $7 \%$ of the PP trial participants discontinuing due to illness, no longer wishing to participate or moving to a health centre not participating in the trial (Table 5).

\section{Methodological quality of the included trials}

A meta analysis of trial data was not possible due to the heterogeneity in trial design and outcomes reported. Data related to trial quality was therefore subject to narrative synthesis. Trial quality was assessed using the Critical Appraisal Skills Programme RCT checklist and all trials were considered to be of high quality (scores ranging from 7.5 to 9 out of 10). The lack of reporting of research personnel blinding and reasons for participant withdraw from the study were the most commonly recorded methodological weaknesses. Two of the RCTs also failed to provide details of the required sample size and/or to comment upon whether the study was adequately powered to detect a significant difference between the two study arms [31, 32].

\section{Discussion}

\section{Summary of main findings}

This review identified two behavioural interventions that were effective in achieving $\geq 50 \%$ adherence to a diet intervention and encouraging change in fruit and vegetable 
intake in colorectal adenoma patients. The effective diet interventions were grounded in social cognitive theory with the initial intervention counselling session being delivered individually during a clinic based consultation. These interventions also encouraged participants to identify social support and provided personalised, printed educational materials and recipes to aid behavioural change.

However, the physical activity interventions reviewed did not achieve similar levels of adherence to the goals of the intervention and as such, were ineffective for promoting increased physical activity in colorectal adenoma patients. Inaccuracies in self reporting of adherence due to recall bias and discrepancies between researcher and participant definition of moderate intensity activity may explain low adherence rates to these physical activity interventions. Of additional note is the lack of involvement of an exercise specialist in development and/or delivery of these physical activity interventions.

Intervention adherence could not be compared across all five RCTs due to either lack of reporting or heterogeneity in reporting. Furthermore, full intervention adherence was not achieved in any of the RCTs reviewed.

Of particular note, the follow-up rate in all five trials was high which may indicate that some aspects of the interventions used in these trials are acceptable to this patient group. However since the trials all employed complex interventions and do not report adherence to individual components of the intervention it is difficult to identify which of the components were more acceptable than others.

Overall, data relating to intervention adherence and reasons for drop out provided little insight with respect to the characteristics of the interventions to which this patient group are most likely to adhere. The five RCTs reviewed were relatively homogeneous with respect to the demographics of the populations studied and the nature, content and target recommendations of the behavioural interventions. However, these RCTs were heterogeneous regarding the timing of the intervention in relation to the diagnosis of colorectal adenoma, the duration of the RCT and the intensity of delivery of the intervention. Overall, the methodological quality of the included RCTs was good.

The physical activity and diet interventions were very similar with respect to the behavioural, educational and affective strategies employed to promote behavioural change. Furthermore, these strategies have been shown to be effective in increasing adherence to physical activity in cancer patients and survivors [37, 38]. The reasons why the physical activity interventions were less effective in this population are therefore unclear. It is possible that colorectal adenoma patients perceive change in diet to be more easily achievable than change in physical activity, and as such, require greater motivation, self efficacy and confidence to adhere to target recommendations for physical activity. A more structured, maximum contact, patient focused, physical activity programme than that provided by the PREVENT and BHBH interventions may therefore be necessary to promote adherence in this patient group.

There is evidence to suggest that colorectal adenoma patients are largely unaware of the implications of their diagnosis and may not view themselves as being at increased risk of colorectal cancer [39-42]. Since people are more amenable to behaviour change following a health event or scare [43], it is possible that improved communication of personal risk with respect to recurrence of colorectal adenoma and progression to colorectal cancer at the time of colorectal adenoma diagnosis will enhance adherence to behavioural interventions in this population. Personalized risk information was provided in one of the behavioural interventions; unfortunately this intervention was ineffective with regard to promoting adherence or change in this population. However this intervention did target five other risk factors for colorectal adenoma recurrence in addition to encouraging increased physical activity. This provides another possible reason why it was ineffective for promoting change in physical activity in colorectal adenoma patients. Interventions promoting change in multiple risk factors are inherently more complex to deliver and assess and results are more difficult to interpret. From the patient perspective, change in multiple behaviours is also much more challenging and additional barriers and facilitators to change need to be considered when designing behavioural interventions to promote change in multiple risk factors.

\section{Strengths and limitations}

This is the first systematic review to examine behavioural intervention programmes and determine adherence to interventions which promote change in diet and/or physical activity in adenoma patients. As such, this review has provided a useful insight into the ability of adenoma patients to adhere to diet and physical activity interventions. Further research is however required to identify physical activity interventions to which colorectal adenoma patients are likely to adhere. Only three of the five RCTs eligible for inclusion in this review examined the impact of a behavioural intervention upon physical activity making it difficult to draw any meaningful conclusions. Moreover, only one RCT promoting a reduction in red meat consumption was identified meaning the aims of this review were not fully met. However, this review did capture all RCTs of diet and/or physical activity in colorectal adenoma patients published in the last 14 years. There is a risk of publication bias because unpublished RCTs were not included. Similarly, limiting 
literature searches to English language publications may impact upon language bias. However, the effect of this is likely to be small as it is unlikely many if any studies were missed that would have been included in this review.

\section{Conclusion}

This review identified two interventions which were effective in colorectal adenoma patients for promoting change in diet and successfully achieved at least $50 \%$ adherence to the goals of the diet intervention. However, this review failed to identify effective interventions for promoting adherence to physical activity in this patient group. Derivation of a physical activity intervention to which colorectal adenoma patients are likely to adhere was, therefore, not possible. Future research should focus upon interventions promoting change in physical activity alone and which involve an exercise specialist in the design and delivery of the intervention. Provision of personalized risk information should also be considered to promote adherence to physical activity interventions in this patient group.

\begin{abstract}
Abbreviations
BHBH: Bowel Health for Better Health; CPRU: Cancer Prevention Research Unit; HRA: High Risk Adenoma; NIHR RfPB: National Institute for Health Research, Research for Patient Benefit; NHSBCSP: National Health Service Bowel Cancer Screening Programme; PP: Polyp Prevention; RCT: Randomised Controlled Trial.
\end{abstract}

\section{Competing interests}

The authors declare that they have no competing interests.

\section{Authors' contributions}

This review was designed by SW, AJD and GD. JJ, RH and GD undertook the searches. JJ, RH, GD and DM applied the selection criteria. AS and DM undertook data extraction. $\mathrm{RH}$ and $\mathrm{J} J$ assessed the quality of the included studies. All authors contributed to data interpretation. DM wrote the first draft of this paper and all authors were responsible for subsequent critical revision of the manuscript. GD is the corresponding author for this manuscript. All authors read and approved the final manuscript.

\section{Acknowledgements}

This study is funded by NIHR-RfPB. This manuscript reports independent research commissioned by the National Institute for Health Research. The views expressed in this publication are those of the authors and not necessarily those of the NHS, National Institute for Health Research or the Department of Health. The University of Birmingham was the study sponsor.

\section{Author details}

'Primary Care Clinical Sciences, School of Health and Population Sciences, University of Birmingham, Edgbaston, Birmingham B15 2TT, UK. ${ }^{2}$ Critical Care and Perioperative Medical Research Group, Queen Mary University of London, Mile End Road, London E1 4NS, UK. ${ }^{3}$ School of Medical and Dental Sciences, University of Birmingham, Edgbaston, Birmingham B15 2TT, UK.

Received: 22 May 2015 Accepted: 19 June 2015

Published online: 07 July 2015

\section{References}

1. Bowel cancer incidence statistics http://www.cancerresearchuk.org/healthprofessional/cancer-statistics/statistics-by-cancer-type/bowel-cancer Accessed 17th January 2013

2. Cancer Research UK: UK Bowel Cancer Statistics http:// infocancerresearchukorg/cancerstats/types/bowel/?a $=5441$ accessed 4th July 20082007.
3. NHS Bowel Cancer Screening Programme: NHS Cancer Screening Programmes. http://www.cancerscreening.nhs.uk/bowel/bowel-cancerscreening-purpose.html (accessed July 2008).

4. Baron JA, Sandler RS, Bresalier RS, Quan H, Riddell R, Lanas A, et al. A randomized trial of rofecoxib for the chemoprevention of colorectal adenomas. Gastroenterology. 2006;131:1674-82.

5. Meat and Education.com: World Cancer Research Fund Report: Response from meat industry. http://www.bmesonline.org.uk/features/ wcrf_report_response.php. Accessed on 7 July 2008.

6. Slattery ML. Physical activity and colorectal cancer. Sports Med. 2004;34:239-52.

7. Hirose K, Tajima K. Evidence in favour of lifestyle intervention for cancer prevention with special reference to colorectal cancer. Environ Health Prev Med. 2004;9:130-6.

8. Denlinger CS, Engstrom PF. Colorectal cancer survivorship: movement matters. Cancer Prev Res (Phila). 2011;4:502-11.

9. Chan AT, Giovannucci EL. Primary prevention of colorectal cancer. Gastroenterology. 2010;138:2029-43.

10. Sandhu MS, White IR, McPherson K. Systematic review of the prospective cohort studies on meat consumption and colorectal cancer risk: a meta-analytical approach. Cancer Epidemiol Biomarkers Prev. 2001;10:439-46.

11. Beaton R, Pagdin-Friesen W, Robertson C, Vigar C, Watson H, Harris SR. Effects of exercise intervention on persons with metastatic cancer: a systematic review. Physiother Can. 2009;61:141-53.

12. Bicego D, Brown K, Ruddick M, Storey D, Wong C, Harris SR. Effects of exercise on quality of life in women living with breast cancer: a systematic review. Breast J. 2009;15:45-51.

13. Cheema B, Gaul CA, Lane K, Fiatarone Singh MA. Progressive resistance training in breast cancer: a systematic review of clinical trials. Breast Cancer Res Treat. 2008:109:9-26.

14. Courneya KS, Vallance JK, McNeely ML, Karvinen KH, Peddle CJ, Mackey JR. Exercise issues in older cancer survivors. Crit Rev Oncol Hematol. 2004;51:249-61.

15. Galvao DA, Newton RU. Review of Exercise Intervention Studies in Cancer Patients. J Clin Oncol. 2005;23:899-909.

16. Kirshbaum MN. A review of the benefits of whole body exercise during and after treatment for breast cancer. J Clin Nurs. 2007;16:104-21.

17. Knols R, Aaronson NK, Uebelhart D, Fransen J, Aufdemkampe G. Physical exercise in cancer patients during and after medical treatment: a systematic review of randomized and controlled clinical trials. J Clin Oncol. 2005;23:3830-42.

18. Maddocks M, Mockett S, Wilcock A. Is exercise an acceptable and practical therapy for people with or cured of cancer? A systematic review. Cancer Treat Rev. 2009;35:383-90.

19. McNeely ML, Campbell KL, Rowe BH, Klassen TP, Mackey JR, Courneya KS. Effects of exercise on breast cancer patients and survivors: a systematic review and meta-analysis. CMAJ. 2006;175:34-41.

20. Oldervoll LM, Kaasa S, Hjermstad MJ, Lund JA, Loge JH. Physical exercise results in the improved subjective well-being of a few or is effective rehabilitation for all cancer patients? Eur J Cancer. 2004:40:951-62.

21. Schmitz K, Holtzman J, Courneya K, Masse L, Duval S, Kane R. Controlled Physical Activity Trials in Cancer Survivors: A Systematic Review and Meta-analysis. Cancer Epidemiol Biomarkers Prev. 2010;14:1588-95.

22. Halfdanarson TR, Thordardottir E, West CP, Jatoi A. Does dietary counseling improve quality of life in cancer patients: a systematic review and meta-analysis (Provisional abstract). J Support Oncol. 2008;6:234-7.

23. Speck R, Courneya K, Masse L, Duval S, Schmitz K. An update of controlled physical activity trials in cancer survivors: a systematic review and meta-analysis. J Cancer Surviv. 2010;4:87-100.

24. Spence R, Heesch K. Exercise and cancer rehabilitation: a systematic review. Cancer Treat Rev. 2010;36:185-94.

25. Stevinson C, Lawlor DA, Fox KR. Exercise interventions for cancer patients: systematic review of controlled trials. Cancer Causes Control. 2004;15:1035-56.

26. Robiner WN. Enhancing adherence in clinical research. Contemp Clin Trials, 2005;26:59-77.

27. Ellis $S$, Shumaker S, Sieber W, Rand C. Adherence to pharmacologica interventions. Current trends and future directions. The Pharmacological Intervention Working Group. Control Clin Trials. 2000;21:218S-25S.

28. Martin KA, Bowen DJ, Dunbar-Jacob J, Perri MG. Who will adhere? Key issues in the study and prediction of adherence in randomized controlled trials. Control Clin Trials. 2000;21:195S-9S. 
29. Critical Appraisal Skills Programme, CASP Randomised Controlled Trials Checklist-http://www.casp-uk.net/\#!checklists/cb36 Last accessed 12/11/12

30. Daley AJ, Stokes-Lampard H, Thomas A, Rees M, Coleman S, Roalfe A, et al Aerobic exercise as a treatment for vasomotor menopausal symptoms: Randomised controlled trial protocol. Maturitas. 2013;76:350-6.

31. Smith Warner SA, Elmer PJ, Tharp TM, Fosdick L, Randall B, Gross M, et al. Increasing vegetable and fruit intake: randomized intervention and monitoring in an at-risk population. Cancer Epidemiol Biomarkers Prev. 2000;9:307-17

32. Lanza E, Schatzkin A, Daston C, Corle D, Freedman L, Ballard Barbash R, et al. Implementation of a 4-y, high-fiber, high-fruit-and-vegetable, low-fat dietary intervention: results of dietary changes in the Polyp Prevention Trial. Am J Clin Nutr. 2001;74:387-401.

33. Emmons KM, McBride CM, Puleo E, Pollak Kl, Clipp E, Kuntz K, et al. Project PREVENT: a randomized trial to reduce multiple behavioral risk factors for colon cancer. Cancer Epidemiol Biomarkers Prev. 2005;14:1453-9.

34. Caswell S, Anderson AS, Steele RJ. Bowel health to better health: a minimal contact lifestyle intervention for people at increased risk of colorectal cancer. Br J Nutr. 2009;102:1541-6.

35. Anderson AS, Craigie AM, Caswell S, Treweek S, Stead M, Macleod M, et al. The impact of a bodyweight and physical activity intervention (BeWEL) initiated through a national colorectal cancer screening programme: randomised controlled trial. BMJ. 2014;348.

36. Sansbury LB, Wanke K, Albert PS, Kahle L, Schatzkin A, Lanza E, et al. The effect of strict adherence to a high-fiber, high-fruit and -vegetable, and low-fat eating pattern on adenoma recurrence. Am J Epidemiol. 2009;170:576-84.

37. Rajarajeswaran P, Vishnupriya R. Exercise in cancer. Indian J Med Paediatr Oncol. 2009;30:61-70.

38. Szymlek-Gay EA, Richards R, Egan R. Physical activity among cancer survivors: a literature review. N Z Med J. 2011;124:77-89.

39. McBride CM, Puleo E, Pollak Kl, Clipp EC, Woolford S, Emmons KM. Understanding the role of cancer worry in creating a "teachable moment" for multiple risk factor reduction. Soc Sci Med. 2008;66:790-800.

40. Giovannucci E, Ascherio A, Rimm EB, Colditz GA, Stampfer MJ, Willett WC. Physical activity, obesity, and risk for colon cancer and adenoma in men. Ann Intern Med. 1995;122:327-34.

41. Giovannucci E, Colditz GA, Stampfer MJ, Willett WC. Physical activity, obesity, and risk of colorectal adenoma in women (United States). Cancer Causes Control. 1996;7:253-63.

42. Neugut Al, Terry MB, Hocking G, Mosca L, Garbowski GC, Forde KA, et al. Leisure and occupational physical activity and risk of colorectal adenomatous polyps. Int J Cancer. 1996;68:744-8.

43. Schroy 3rd PC, Glick JT, Wilson S, Robinson PA, Heeren TC. Deficiencies in knowledge and familial risk communication among colorectal adenoma patients. J Clin Gastroenterol. 2005;39:298-302.

\section{Submit your next manuscript to BioMed Central and take full advantage of:}

- Convenient online submission

- Thorough peer review

- No space constraints or color figure charges

- Immediate publication on acceptance

- Inclusion in PubMed, CAS, Scopus and Google Scholar

- Research which is freely available for redistribution

Submit your manuscript at www.biomedcentral.com/submit 